\title{
CAN HEALTH PUBLIC EXPENDITURE REDUCE THE TRAGIC CONSEQUENCES OF ROAD TRAFFIC ACCIDENTS? THE EU-27 EXPERIENCE
}

\author{
AUTHORS \\ José I. Castillo-Manzano (jignacio@us.es). \\ University of Seville (Spain)
}

Address: Facultad de Ciencias Económicas y Empresariales, University of Seville (Spain). Avda. Ramón y Cajal, 1. 41018 Sevilla (spain). Tel. +34 95.455.75.38. Fax. +3495.455.76.29

Mercedes Castro-Nuño (mercas@us.es).

University of Seville (Spain)

Address: Facultad de Ciencias Económicas y Empresariales, University of Seville (Spain). Avda. Ramón y Cajal, 1. 41018 Sevilla (spain). Tel. +34 95.455.75.38. Fax. +3495.455.76.29

Xavier Fageda (xfageda@ub.edu).

University of Barcelona (Spain)

Address: Department of Economic Policy (University of Barcelona). Av. Diagonal, 690 08034 Barcelona (Spain). Tel: +34 934039721. FAX: +34 934024573

Keywords: Road Safety, health expenditures, hospital beds density, panel Data.

Jel codes: I100, L91

\begin{abstract}
:
This study uses data for the EU-27 countries in the period 1999-2009 to estimate determinants of road traffic fatality rates. Controlling for country attributes and road safety policy variables, we examine the influence of variables related with the national health systems; the number of hospital beds per kilometer and the percentage of health expenditures over gross domestic product. We find evidence that the density of hospital beds contributes substantially to the fall in traffic-related fatalities. Furthermore, the quality of general medical facilities and technology associated with increases in health expenditure may be also a relevant factor in reducing road traffic fatalities.
\end{abstract}




\section{CAN HEALTH PUBLIC EXPENDITURE REDUCE THE TRAGIC CONSEQUENCES OF ROAD TRAFFIC ACCIDENTS? THE EU-27 EXPERIENCE.}

\section{INTRODUCTION.}

Nowadays road traffic accidents (RTAs) and related injuries tend to be recognized as relevant health public problems and economic concerns in European countries (Racioppi et al., 2004). The European Commission CARE database (EC, 2012), estimates that over 31,000 road users are killed annually due to RTAs in the European Union 27 (EU-27), which is equivalent to the population of The Republic of San Marino or The Principality of Monaco. Road safety has become a major issue in EU common transport policies (Threlfall, 2003) within the framework of the four European Road Safety Action Programmes (ERSAP). According to statistical sources (ETSC, 2011) extraordinary improvements have been achieved during recent years, through the acquis of strategies implemented by member States and the European Authorities.

Several studies have analyzed factors that may be statistically significant for explaining the fall in European accidents rates (Herrero Blanco et al. 2011; Orsi et al. 2012) with variables linked to level of economic activity or to preventive actions (active safety): traffic safety policies or related to investment in and maintenance of safer roads and vehicles. Much of this work agrees in also associating reductions in traffic-related fatalities with so-called passive safety, in reference to the effectiveness of post-accident care (Gitelman et al., 2012; Noland, 2003): i.e., advances in recent decades in National Health Systems (NHS) that provide better emergency services and vehicles (Elvik et al. 2009); advanced trauma care (Bishai et al. 2006; Gitelman et al. 2012); new medical technology and treatments (Noland \& Quddus, 2004); greater availability of hospitals, hospital beds and personnel (Anwaar et al. 
2012); and faster and better pre-hospital care with a considerable reduction in the so-called “Golden Hour” (Arroyo et al. 2012; Sánchez-Mangas et al. 2010).

However, despite of the European Commission's harmonization efforts (such as the eCall system, EC, 2011) and the real convergence of EU members' health policies over the last 30-40 years (Cucic, 2000; Wörz \& Busse, 2005), significant differences can still be detected between the various NHS (Hitiris, 1997; Przywara, 2010): different health public spending patterns, differences in legislation on emergency services (medical response time guaranteed by law in several countries) and their financing (included in the driver's private insurance or by government coverage). In short, different health-care systems may reflect different health outcomes (Nixon \& Ulmann, 2006) and different levels of road safety performance, which in turn are also influenced by each State's own socio-political, economic and historical evolution, according to Orsi et al. (2012).

This study uses data for the EU-27 countries in the period 1999-2009 to estimate the determinants of road fatality rates. Controlling for country attributes and road safety policy variables, the main goal is to examine the extent to which differences between member States in road traffic fatally rates can be attributed to changes or disparities in the planning of national health-care systems (considered as a whole).

Prior research indicates that improvements in health management have contributed to better injury outcomes, although no definitive conclusions can be drawn because the relationship with tragic road crash outcomes has been analyzed by relatively few studies and only partial aspects of the NHS are considered (i.e., post-impact care and medical technology; see the meta-analysis by Elvik et al. 2009).

Therefore our aim is to evaluate the contribution made by some typical factors associated with reductions in RTA consequences and provide evidence for the causal link between

\footnotetext{
${ }^{1}$ This concept refers to the care response timeframe after a RTA and is described as "crucial" by the literature for survival or reducing injuries (see Gitelman et al. 2012) (the first 60 minutes post-collision).
} 
health-care expenditure made by EU governments and traffic safety outcomes. Nixon \& Ulmann (2006) acknowledge the difficulty of isolating the contribution of the health service as a determinant (input) of health status (output) in general. Other authors, such as Gitelman et al. (2012), suggest the need to carry out studies to evaluate the relationship between healthcare performance and road safety outcomes.

Thus, the crucial variables in our analysis identify differences across European countries in health systems. In particular, we consider the following health related variables; the number of hospital beds per kilometer and the percentage of health expenditures over gross domestic product.

In this regard, we propose to identity empirically the effect of variables that may increase the speed and effectiveness of health treatment to injured victims in road accidents. Here, it is not just the availability of hospital beds nearby that is relevant, but also all the health services associated with them, such as ambulances and trauma services.

Hence, we seek to test whether investing in a health system beyond what should be expected according to a country's level of economic development (detected by the per capita gross domestic product) has positive effects on the reduction in road traffic fatality rates, as Noland (2003) states. This should especially be the case when the investment is directed at developing a dense hospital network (with associated health services) that takes into account not only the volume of the population, but also the size of the country.

Furthermore, we analyze the effect of health public expenditure as a percentage of the Gross Domestic Product as a proxy variable of overall domestic improvements in health systems made by member countries. In this respect, the econometric estimation obtained by Herrero Blanco et al. (2011) suggests that fatality rates in the EU (not the accident rate) are more closely linked to domestic health expenditure than the per capita income level. Although a negative and statistically significant correlation is obtained for both variables with respect to 
road fatality and injury rates, the effect is much higher in the case of health expenditure. Therefore, we assume the hypothesis established by these authors and confirmed by Anwaar et al. (2012) and Bishai et al. (2006): the correlation between the level of economic development and road fatality rates is conditioned by specific components of this economic progress, such as all the different ways in which advances in health policies can be expressed through the general concept of public spending.

Our analysis will also enable us to test the Noland (2003) hypothesis on the European scale, i.e., that the increased motorization rates that have resulted from economic growth may cause a rise in traffic fatalities, but when a certain level of development has been reached, the quality and accessibility of health facilities and resources have an indirect effect on road users' attitudes to risk (Grimm \& Treibich, 2012).

The paper is structured as follows. After this introduction, Section 2 describes the data, variables and empirical model based on panel data methodology. Section 3 discusses the major findings and their implications and Section 4 lays out the main conclusions of our study.

\section{THE EMPIRICAL ANALYSIS.}

In our empirical analysis, we use EU-27 data for the 1999-2009 period. We develop a twoway fixed effects model that takes the following form for country $i$ during period $t$ :

$$
\mathrm{Y}_{\mathrm{it}}=\alpha+\beta_{\mathrm{k}} \mathrm{X}_{\mathrm{it}}+\lambda_{\mathrm{k}}, \mathrm{Z}_{\mathrm{it}}+\mu_{\mathrm{i}}+v_{\mathrm{t}}+\varepsilon_{\mathrm{it}}
$$

where $Y_{i t}$ is the $\log$ of the total per capita fatality rate (within 30 days of the accident according to the Vienna Convention definition) ${ }^{2}, \mathrm{X}_{\mathrm{it}}$ contains the vector of the country's economic attributes and $Z_{i t}$ are road safety policy-related variables. $\mu_{i}$ are country fixed

\footnotetext{
${ }^{2}$ Albalate (2008), Albalate \& Bel (2011), Dee (2001) and Eisenberg (2003) consider that this is the most appropriate dependent variable for assessing road traffic fatalities as the interpretation of policy variables is clearer.
} 
effects that control for time-invariant country-specific omitted variables, $v_{\mathrm{t}}$ are year dummies that control for national trends and $\varepsilon_{\mathrm{it}}$ is a mean-zero random error.

The time variation of the policy variables that we consider is low for most countries and in some cases there is no variation at all in the period analyzed. Hence, we apply two different strategies to take into account the country-fixed effects. ${ }^{3}$ Firstly, we perform the estimation using the ordinary least squares method including dummies for countries and years. With this strategy we can include policy variables with low time variability as covariates. Secondly, the data used for estimating the determinants of road traffic fatalities have a data panel structure. Hence, we also estimate a fixed effects model that exploits the within variation of the data. An advantage of the fixed effects model is that it allows us to control for any omitted variable which is correlated with the variables of interest and does not change over time. A shortcoming of the fixed effects model is that it may not consider time-constant variables (or those with a very low within variation) as explanatory variables. Thus, the estimation with the fixed effects model does not include either the policy variables or the country dummies ${ }^{4}$.

Furthermore, the estimates can present heteroscedasticity and temporal autocorrelation problems in the error term. The Wooldridge test for autocorrelation in panel data shows that we may have a problem of serial autocorrelation that must be addressed. However, the Breusch-Pagan/Cook-Weisberg test indicates that we do not have a problem of heteroscedasticity. Following Bertrand et al. (2004), our standard errors are clustered by country to take into account the correlation between the same country observations.

Table 1 provides the descriptions, information sources and descriptive statistics (mean and standard deviation) of the explanatory variables.

\footnotetext{
${ }^{3}$ Depending on the distribution of the dependent variable, the estimation should be done using negative binomial distribution (see, for example, Anbarci et al. 2006). In our case, the wide dispersion of our dependent variable and the small number of observations does not allow this method to be used. We have run some regressions using a negative binomial distribution and no variable is statistically significant (results are available from the authors upon request).

${ }^{4}$ The Hausman test shows that systematic differences are found between the random and fixed effects and thus the fixed effects model should be preferred to the random effects model.
} 


\section{[INSERT TABLE 1]}

The main variables in our analysis are health policy-related. Based on other studies on this issue which seem to confirm a positive link between health care expenditure and several health outcomes (see Nixon \& Ulmann, 2006 for the EU) we include as an explanatory variable the total expenditure on health as a percentage of the gross domestic product. Following the Maio et al. (1992) criterion we also include the number of hospital beds per kilometer. We expect a negative sign for the coefficients associated with these variables. In this case, the health variables would contribute to the reduction in road traffic fatality rates, as stated by Anwaar et al. (2012).

There may be a simultaneous determination of road fatalities and health expenditure that could cause a bias in the estimation. To deal with this, we include a one-year lag of health expenditure as an explanatory variable.

In line with Orsi et al. (2012) we also consider typical variables used for road traffic fatalities related to the country's economic conditions found in the empirical literature. In this regard, we include the per capita gross domestic product as an indicator of the country's economic development (García-Ferrer et al. 2007). Kopits \& Cropper (2005) and Anbarci et al. (2006) find evidence of a non-linear relationship between road fatalities and economic development using samples that include developed and developing countries from all over the world. Indeed, fatality rates may increase with economic development in very poor countries due to increased exposure to road traffic accidents. However, as Bishai et al. (2006) specify, the relationship between economic development and traffic fatality rates may become flat or even decrease after reaching a certain wealth threshold. We test the hypothesis concerning 
non-linearity between GDP and traffic fatalities by including the GDP and the square of the GDP as explanatory variables.

The country's level of motorization is also taken into account. This variable is related to the development of private transportation. It is not clear what relationship with road traffic fatalities should be expected. On the one hand, higher levels of motorization may imply higher exposure to road traffic accidents. On the other hand, more developed countries may enjoy better infrastructure and vehicles, better policies and better social attitudes towards road safety, confirming what is known as Smeed's Law (Smith, 1999).

The number of passengers-kilometer weighted by country population is an additional explanatory variable in our model. This variable seeks to capture the intensity of traffic on the roads. In this regard, we could expect a positive relationship between the amount of traffic and road fatalities since the total amount of driving is an indication of the population's exposure to road accident risks (Orsi et al. 2012). However, as Li et al. (2012) find, such a relationship could be dependent upon congestion levels. We also include motorway density as an explanatory variable. This is an indicator of the quality of transport infrastructure. We may expect a negative relationship between the quality of transport infrastructure and road traffic fatality rates.

Along with countries' economic attributes, we also consider additional variables for road safety policies. Firstly, following the prior literature on road accidents (Albalate, 2008; Castillo-Manzano \& Castro-Nuño, 2012; Eisenberg, 2003), we include a dummy variable that takes a value of one for countries and periods where the maximum blood alcohol concentration rate allowed is lower than 0.5 . In our context, most of the countries have set the limit at 0.5 or lower, so we are able to test whether blood alcohol concentration rates lower than 0.5 are effective in reducing road traffic fatalities. Secondly, we include a dummy variable that takes a value of one for countries and periods with points-based driving licenses. 
With this variable we can test the effectiveness of this policy for reducing road traffic fatalities. Finally, we consider a variable that shows the maximum speed limit allowed on motorways. Following researchers such as Elvik (2012), we may expect a positive relationship between the speed limit (and its subsequent enforcement) and road traffic fatalities.

\section{RESULTS AND DISCUSSION.}

Table 2 provides the results of the estimates of the determinants of road traffic fatalities equation. We find no substantial differences in the results whichever estimation technique is used.

\section{[INSERT TABLE 2]}

In line with prior results by Bishai (2006) and Grimm \& Treibich (2012) we find evidence of a non-linear relationship between road traffic fatality rates and countries' economic development. Indeed, the coefficient associated with the GDP variable is positive and statistically significant, while the square of the same variable is negative and also statistically significant. However, the level of motorization variable is not statistically significant. It may be the case that the influence of this variable is already captured by the GDP variables. We also find that the coefficient associated with motorway density is negative and statistically significant, which confirms that the quality of transport infrastructure has a significant effect on road safety, as in Jamroz (2012). Furthermore, the variable of vehicles-kilometer driven is positive but not statistically significant. In the line of Li et al. (2012), more traffic on the roads implies higher exposure to accidents but this effect may be partially compensated for by lower speeds (and therefore less severe accidents) due to congestion. 
Concerning road safety policies, those related to the maximum blood alcohol concentration rate and speed limits seem to be effective in reducing traffic fatality rates. Surprisingly, the sign of the coefficient associated with the points-based driving license policy is not what was expected, perhaps due to the lack of harmonization of the structure and the period of implementation among the member States. In any case, the unexpected result for this variable may be an indication of little relevance of the points-based driving policy. In this regard, the real effectiveness of this measure is starting to be questioned, especially some months after the passing of the measure (see Castillo-Manzano \& Castro-Nuño, 2012, for a recent metaanalysis about the effects of this policy).

Importantly, the coefficients associated with both the variables of health expenditure and the density of hospital beds are negative and statistically significant at $5 \%$ and $1 \%$ respectively. Table 3 gives the health variable elasticities obtained from the estimates.

[INSERT TABLE 3]

We find that a $10 \%$ increase in health expenditure (as a percentage of the GDP) implies a decrease in traffic fatality rates of about $4.5 \%$. Additionally, a $100 \%$ increase in the number of hospital beds per kilometer implies a decrease in traffic fatality rates of about $3 \%$. Thus, we confirm that countries that provide a better geographical coverage of health care for road accidents are able to reduce the likelihood of death once the accident has taken place (Buchmueller et al. 2006) by enabling a quick medical response and pre-hospital care (Arroyo et al. 2013; Sánchez-Mangas et al. 2010; Wilde, 2012). This effect is relevant not just in statistical terms (the coefficients associated with these variables are statistically significant) but also from a quantitative point of view because the derived elasticities are quite high. As pointed out by Grimm \& Treibich (2012), the density of hospital beds contributes to the fall in traffic-related fatalities and lower injury severity but the main issue may not be this, but rather 
the quality of general medical facilities and technology associated with increases in health expenditure (Bishai et al., 2006; Noland \& Quddus, 2004).

\section{CONCLUDING REMARKS.}

In this paper, we have shown and quantified the way in which the quantity and quality of the health system affects road traffic fatality reductions in the EU-27. In order to reach this conclusion, we have controlled for several variables that are also significant and which are related to the country's economic development, the quality of its infrastructure, the amount of road traffic and policies such as maximum blood alcohol content and speed limits. 


\section{REFERENCES}

Albalate, D. 2008. Lowering Blood Alcohol Content Levels to Save Lives: The European Experience. Journal of Policy Analysis and Management 27: 20-39.

Albalate, D., Bel, G. 2011. Motorways, tolls, and road safety: Evidence from Europe'. SERIEs: Journal of the Spanish Economic Association. doi: 10.1007/s13209-0110071-6.

Anbarci, N., Escaleras, M., Register, C. 2006. Traffic Fatalities and Public Sector Corruption. Kyklos 59: 327-344.

Anwaar, A., Anastasopoulos, P., Ping Ong, G., Labi, S., Bin Islam, M. 2012. Factors affecting highway safety, health care services, and motorization-An exploratory empirical analysis using aggregate data. Journal of Transportation Safety \& Security 4: 94-115.

Arroyo, A.S.M., García-Ferrer, A., De Juan Fernández, A., Sánchez-Mangas, R. 2013. Lower posterior death probabilities from a quick medical response in road traffic accidents. Journal of Applied Statistics 40: 40-58.

Bertrand, M., Duflo, E., Mullainathan, I. 2003. How much should we trust differences-indifferences estimates? The Quarterly Journal of Economics 119: 249-275.

Bishai, D., Quresh, A., James, P., Ghaffar, A. 2006. National road casualties and economic development. Health Economics 15: 65-81.

Buchmueller, T. C., Jacobson, M., Wold, Ch. 2006. How far to the hospital? The effect of hospital closures on access to care. Journal of Health Economics 25: 740-761.

Castillo-Manzano, Castro-Nuño, M. 2012. Driving licenses based on points systems: Efficient road safety strategy or latest fashion in global transport policy? A world wide metaanalysis. Transport Policy 21: 191-201.

Cucic, S. 2000. European Union health policy and its implications for national convergence. International Journal for Quality in Health Care 12: 217-225.

Dee, T.S. 2001. Does setting limits save lives? The case of 0.08 BAC laws. Journal of Policy Analysis and Management 20:111-118.

Eisenberg, D. 2003. Evaluating the effectiveness of policies related to drunk driving. Journal of Policy Analysis and Management 22: 249-274.

Elvik, R., Vaa, T., Sorensen, M. 2009. The Handbook of Road Safety Measures, $2^{\text {nd }}$ ed. Emerald Group Publishing Ltd.

Elvik, R. 2012. Speed limits, enforcement and health consequences. Annual Review of Public Health 33: 225-238.

European Commission (EC) 2011. Commission recommendation on support for an EU-wide eCall service in electronic communication networks for the transmission of in-vehicle emergency calls based on 112 ('e-Calls'). SEC 1019 final. Brussels.

European Commission (EC) CARE Database 2012. National data of EU road fatalities. Annual evolution since 2001. Directorate General for Mobility and Transport. Brussels.

European Transport Safety Council (ETSC) 2011. Roadmap to a single European Transport Area- Towards a competitive and resource efficient transport system. ETSC Response to the European Commission White Paper. Brussels. 
García-Ferrer, A., De Juan, A., Poncela, P. 2007. The relationship between road traffic accidents and real economic activity in Spain: Common cycles and health issues. Health Economics 16: 603-626.

Gitelman, V., Auerbach, K., Doveh, E. 2012. Development of road safety performance indicators for trauma management in Europe. Accident Analysis and Prevention, doi: 10.1016/j.aap.2012.08.006.

Grimm, M., Treibich, C. 2012. Determinants of road traffic crash fatalities across Indian States. Health Economics, doi: 10.10002/hec.2870.

Herrero Blanco, C., Abellán Perpinán, J.M., Cubí Mollá, P. Martínez Pérez, J.E., Méndez Martínez, I., Sánchez Martínez, F.I. 2011. Siniestralidad vial en España y la Unión Europea (1997-2007). Fundación BBVA. Spain.

Hitiris, T. 1997. Health care expenditure and integration in the countries of the European Union. Applied Economics 29: 1-6.

Jamroz, K. 2012. The impact of road network structure and mobility on the national traffic fatality rate. Procedia-Social and Behavioral Sciences 54: 1370-1377.

Kopits, E., Cropper, M. 2005. Traffic fatalities and economic growth. Accident analysis and Prevention 37: 169-178.

Li, H., Graham, D.J., Majumdar, A. 2012. The effects of congestion charging on road traffic casualties: A causal analysis using difference-in-difference estimation, Accident Analysis and Prevention 49: 366-377.

Maio, R.F., Green, P.E., Becker, M.P., Burney, R.E. 1992. Rural motor vehicle crash mortality: The role of crash severity and medical resources. Accident Analysis and Prevention 24: 631-642.

Nixon, J., Ulmann, Ph. 2006. The relationship between health care expenditure and health outcomes. European Journal of Health Economics 7: 7-18.

Noland, R.B. 2003. Medical treatment and traffic fatality reductions in industrialized countries. Accident Analysis and Prevention 35: 877-883.

Noland, R.B., Quddus, M.A. 2004. Improvements in medical care and technology and reductions in traffic-related fatalities in Great Britain. Accident Analysis and Prevention 36: 103-113.

Orsi, Ch., Bertuccio, P., Morandi, A., Levi, F., Bosetti, C., La Vecchia, C. 2012. Trends in motor vehicle crash mortality in Europe, 1980-2007. Safety Science 50: 1009-1018.

Przywara, B. 2010. Projecting future health care expenditure at European level: drivers, methodology and main results. European Economy, Economic Papers 417, July. Economic and Financial Affairs, European Commission. Brussels.

Racioppi, F., Eriksson, L., Tingvall, C., Villaveces, A. 2004. Preventing road traffic injury: a public health perspective for Europe. World Health Organization (WHO) Regional Office for Europe. Denmark. 
Sánchez-Mangas, R., García-Ferrer, A., De Juan, A., Martín Arroyo, A. 2010. The probability of death in road traffic accidents. How important is a quick medical response? Accident Analysis and Prevention 42: 1048-1056.

Smith, I. 1999. Road fatalities, modal split and Smeed's law. Applied Economics Letters 6: 215-217.

Threlfall, M. 2003. European Social Integration: Harmonization, Convergence and Single Social Areas. Journal of European Social Policy 13: 121-139.

Wilde, E.TY. 2012. Do emergency medical system response times matter for health outcomes? Health Economics, doi: 10.1002/hec.2851.

Wörz, M., Busse, R. 2005. Analysing the impact of health-care system change in the EU member states-Germany. Health Economics 14: S133-S149. 
TABLE 1. Variables used in the empirical analysis

\begin{tabular}{|c|c|c|c|c|}
\hline Variables & Description & Source & Mean & $\begin{array}{l}\text { Standard } \\
\text { Deviation }\end{array}$ \\
\hline Per capita fatalities & $\begin{array}{c}\text { Fatality rates per million } \\
\text { inhabitants }\end{array}$ & $\begin{array}{c}\text { CARE (EU road accidents } \\
\text { database) }\end{array}$ & 110.61 & 45.32 \\
\hline Health_expenditure & $\begin{array}{c}\text { Total expenditure on health as } \\
\text { a percentage of the gross } \\
\text { domestic product }\end{array}$ & $\begin{array}{l}\text { WHO (Global health } \\
\text { observatory data } \\
\text { repository) }\end{array}$ & 8.00 & 1.64 \\
\hline Bed density & Total hospital beds per km & $\begin{array}{l}\text { Eurostat and World } \\
\text { Bank Statistics }\end{array}$ & 9757 & 41523 \\
\hline Per capita GDP & $\begin{array}{l}\text { Per capita gross domestic } \\
\text { product in International } \\
\text { Comparable Prices (US\$ at } \\
2005 \text { prices and PPP) }\end{array}$ & $\begin{array}{c}\text { UNECE Statistical } \\
\text { Division Database, } \\
\text { compiled from official } \\
\text { national and international } \\
\text { (CIS, EUROSTAT, IMF, } \\
\text { OECD) sources }\end{array}$ & 25211 & 11738 \\
\hline Motorization & $\begin{array}{c}\text { Number of registered vehicles } \\
\text { per } 1000 \text { inhabitants }\end{array}$ & $\begin{array}{l}\text { UNECE transport division, } \\
\text { Eurostat, World Bank and } \\
\text { national databases }\end{array}$ & 424.27 & 113.57 \\
\hline Vehicles-km driven & $\begin{array}{c}\text { Number of passenger-cars-km } \\
\text { expressed in } 1000 \text { million km } \\
\text { and weighted by national } \\
\text { population }\end{array}$ & $\begin{array}{l}\text { European Commission } \\
\text { (Directorate General for } \\
\text { mobility and transport) }\end{array}$ & 44.21 & 337.56 \\
\hline Motorway density & $\begin{array}{l}\text { Number kms of motorways } \\
\text { divided by square km of the } \\
\text { country }\end{array}$ & EUROSTAT and UNECE & 1.68 & 1.74 \\
\hline BAC_05 & $\begin{array}{l}\text { Dummy variable that takes a } \\
\text { value of } 1 \text { for countries and } \\
\text { periods where the maximum } \\
\text { blood alcohol concentration } \\
\text { rate allowed is less than } 0.5\end{array}$ & $\begin{array}{l}\text { European Commission } \\
\text { Road Safety Website }\end{array}$ & 0.25 & 0.43 \\
\hline PPS & $\begin{array}{l}\text { Dummy variable that takes a } \\
\text { value of } 1 \text { for countries and } \\
\text { periods with a points-based } \\
\text { driving license }\end{array}$ & $\begin{array}{c}\text { SWOV and National } \\
\text { legislation }\end{array}$ & 0.74 & 0.43 \\
\hline Speed limits & $\begin{array}{l}\text { Maximum speed limits } \\
(\mathrm{km} / \text { hour })\end{array}$ & $\begin{array}{l}\text { European Commission } \\
\text { Road Safety Website }\end{array}$ & 121.18 & 13.66 \\
\hline
\end{tabular}


TABLE 2. Results of estimates: Fatality rates per capita

\begin{tabular}{|c|c|c|}
\hline Independent variables & $\begin{array}{c}\mathbf{( 1 )} \\
\text { Fixed effects-within estimator }\end{array}$ & $\begin{array}{c}\mathbf{( 2 )} \\
\text { Ordinary Least Squares }\end{array}$ \\
\hline Health_expenditure & $-0.056(0.0022)^{* *}$ & $-0.056(0.0023)^{* *}$ \\
\hline Bed density & $-3.24 \mathrm{e}-06(0.022)^{* * *}$ & $-3.24 \mathrm{e}-06(5.05 \mathrm{e}-07)^{* * *}$ \\
\hline Per capita GDP & $0.000051(0.000017)^{* * *}$ & $0.000059(0.000017)^{* * *}$ \\
\hline Per capita GDP ${ }^{2 *}$ & $-5.57 \mathrm{e}-10(1.32 \mathrm{e}-10)^{* * *}$ & $-5.57 \mathrm{e}-10(1.40 \mathrm{e}-10)^{* * *}$ \\
\hline Motorway density & $-0.14(0.05)^{* * *}$ & $-0.14(0.006)^{* *}$ \\
\hline Motorization & $-0.0006(0.0004)$ & $-0.0006(0.0004)$ \\
\hline Vehicles-Km driven & $8.57 \mathrm{e}-06(7.70 \mathrm{e}-06)$ & $8.57 \mathrm{e}-06(8.14 \mathrm{e}-06)$ \\
\hline BAC_05 & - & $-0.11(0.03)^{* * *}$ \\
\hline PPS & - & $0.92(0.25)^{* * *}$ \\
\hline Speed limits & - & $0.013(0.004)^{* * *}$ \\
\hline Constant term & $4.68(0.41)^{* * *}$ & $2.30(1.05)^{* *}$ \\
\hline Country fixed effects & NO & YES \\
\hline Time fixed effects & YES & 268 \\
\hline R-Sq. & 0.73 & 0.95 \\
\hline Number observations & 268 & 268 \\
\hline
\end{tabular}

Note 1: Standard errors are given in brackets and clustered at the country level

Note 2: Statistical significance at 1\%(***), 5\%(**), 10\%(*)

TABLE 3. Health variable elasticities (evaluated at sample means)

\begin{tabular}{|c|c|c|}
\hline Independent variables & $\begin{array}{c}\text { (1) } \\
\text { Fixed effects-within } \\
\text { estimator }\end{array}$ & $\begin{array}{c}\text { (2) } \\
\text { Ordinary Least Squares } \\
\text { with all variables }\end{array}$ \\
\hline Health_expenditure & $-0.44(0.17)^{* * *}$ & $-0.44(0.18)^{* * *}$ \\
\hline Bed density & $-0.03(0.004)^{* * *}$ & $-0.03(0.005)^{* * *}$ \\
\hline
\end{tabular}

